\title{
PARTIDA DE UMA NOVA CONFIGURAÇÃO DE REATOR COMPARTIMENTADO ANAERÓBIO/AERÓBIO
}

\author{
J.A. SILVA ${ }^{1}$, G.H.R.SILVA ${ }^{2}$
}

${ }^{1}$ Universidade Estadual Paulista, Departamento de Engenharia Civil e Ambiental

${ }^{2}$ Universidade Estadual Paulista, Departamento de Engenharia Civil e Ambiental

E-mail para contato: jualves.bio@gmail.com, gustavoribeiro@unesp.br

\begin{abstract}
RESUMO - Como o quadro do saneamento básico no Brasil se encontra precário, fazse necessário a procura por sistemas de tratamento de esgoto eficientes e econômicos. Uma alternativa viável é a utilização de reatores compartimentados anaeróbio/aeróbio. O objetivo da pesquisa foi avaliar o comportamento e a eficiência do reator, durante sua partida. O reator foi implantado no campus da Unesp - Bauru/SP e trata esgoto sanitário proveniente do campus de Educação Física, moradia estudantil e Associação dos servidores da UNESP. É composto por 4 câmaras, sendo as três primeiras anaeróbias e a quarta aeróbia, seguida por decantador laminar. Foi realizado monitoramento durante 8 semanas. Durante este período verificou-se uma remoção média de DQO de aproximadamente $60 \%$ na fase anaeróbia e de $76 \%$ de remoção total. Os valores de $\mathrm{pH}$ variaram entre 6,8 e 7,5; a temperatura variou entre $24{ }^{\circ} \mathrm{C}$ e $30^{\circ} \mathrm{C}$, dentro do sistema completo.
\end{abstract}

\section{INTRODUÇÃO}

Problemas relacionados à qualidade da água e saneamento básico se fazem presentes na realidade brasileira em grande escala. Segundo o Instituto Trata Brasil (2014), o Brasil ocupa a $112^{\mathrm{a}}$ posição em um ranking de saneamento entre 200 países, tendo pontuação média inferior às médias da América do Norte, Europa e alguns países da África e do Oriente Médio. A falta de saneamento básico é responsável por diversos problemas sanitários, proliferação de doenças parasitárias e infecciosas e contaminação de mananciais. Dentre as doenças causadas pela falta de esgotamento sanitário, a diarréia é a principal causa de mortalidade infantil e má nutrição, em países em desenvolvimento. Segundo o relatório da UNICEF e da Organização Mundial da Saúde (OMS), realizado em 2009, a diarréia, causada por falta de saneamento básico, é a segunda maior causa de morte em crianças menores de 5 anos de idade.

Vários estudos também têm mostrado que a má nutrição pode acarretar problemas no desenvolvimento cognitivo e no desempenho escolar de crianças. Niehaus et al. (2002) em uma pesquisa realizada com 27 meninas e 20 meninos, com idades entre 6-10 anos, que tiveram casos observados de diarréia nos primeiros 2 anos de vida, concluíram que as funções cognitivas do grupo haviam sido debilitadas. Novas tecnologias de tratamento de efluente com baixo custo e eficientes, voltadas a pequenas comunidades deveriam ser melhores estudadas. Uma nova opção 
com baixo custo, compacta e que não requer grandes quantidades de área e de energia, sendo apropriada para pequenas comunidades é o reator compartimentado anaeróbio/aeróbio. O reator compartimentado anaeróbio/aeróbio apresenta vantagens em relação a sua fácil construção, que envolvem menores custos que outras configurações e além de proporcionar uma boa estabilidade no processo de tratamento devido a sua divisão em câmaras. Mais especificadamente, este sistema de tratamento de esgoto não necessita de nenhum sistema especial de separação de gás e sólidos, apresenta redução do arraste hidráulico de bactérias, devido ao regime de escoamento. Pode ser operado por longos períodos e tempo sem remoção de lodo e possui projeto simples (BOOPATHAY \& TILCHE, 1991, SILVA \& NOUR, 2011).

Segundo Zanella (1999), Silva (2001), Silva \& Nour (2005) e Silva \& Nour (2011) o reator compartimentado anaeróbio/aeróbio mostrou-se promissor no tratamento de esgoto, pela eficiência na remoção de matéria orgânica e sólidos em suspensão e também vantajoso para o uso em pequenas comunidades urbanas e rurais devido a sua configuração e construção simples e facilidade operacional. Netto (2007), que também pesquisou sobre o reator compartimentado anaeróbio/aeróbio com recirculação da fase líquida, obteve altas taxas de eficiência de remoção de matéria orgânica, chegando a valores de DQO de $50 \mathrm{mg}$. $\mathrm{L}^{-1}$. A presente pesquisa avaliou a partida de uma possível alternativa de tratamento de esgoto para pequenas comunidades, por meio de uma nova configuração do reator compartimentado anaeróbio/aeróbio.

\section{MATERIAL E MÉTODOS}

A pesquisa foi desenvolvida no município de Bauru (SP), nas dependências da Universidade Estadual Paulista (UNESP), no Departamento de Educação Física (DEF). A estação de tratamento de esgoto instalada no DEF, é composta por grade, tanques de equalização, sedimentação e tanque de armazenamento para controle de vazão e reator compartimentado anaeróbio/aeróbio com nova configuração, composto por quatro câmaras, construídas com tubulação de PVC. A vazão foi regulada manualmente, 4 vezes por semana. A distribuição das câmaras pode ser observada por meio da Figura 1. As especificações das câmaras podem estão apresentadas na Tabela 1.

Tabela 1 - Especificações das câmaras que compõe o reator compartimentado anaeróbio/aeróbio

\begin{tabular}{ccccc}
\hline Câmara & Altura $(\mathbf{m})$ & Diâmetro $(\mathbf{m m})$ & Volume $(\mathbf{L})$ & Processo de tratamento \\
\hline $\mathbf{1}$ & 0,90 & 600 & 405 & Anaeróbio \\
$\mathbf{2}$ & 0,90 & 300 & 96 & Anaeróbio \\
$\mathbf{3}$ & 0,90 & 300 & 96 & Anaeróbio \\
$\mathbf{4}$ & 1,70 & 400 & 220 & Aeróbio \\
\hline
\end{tabular}




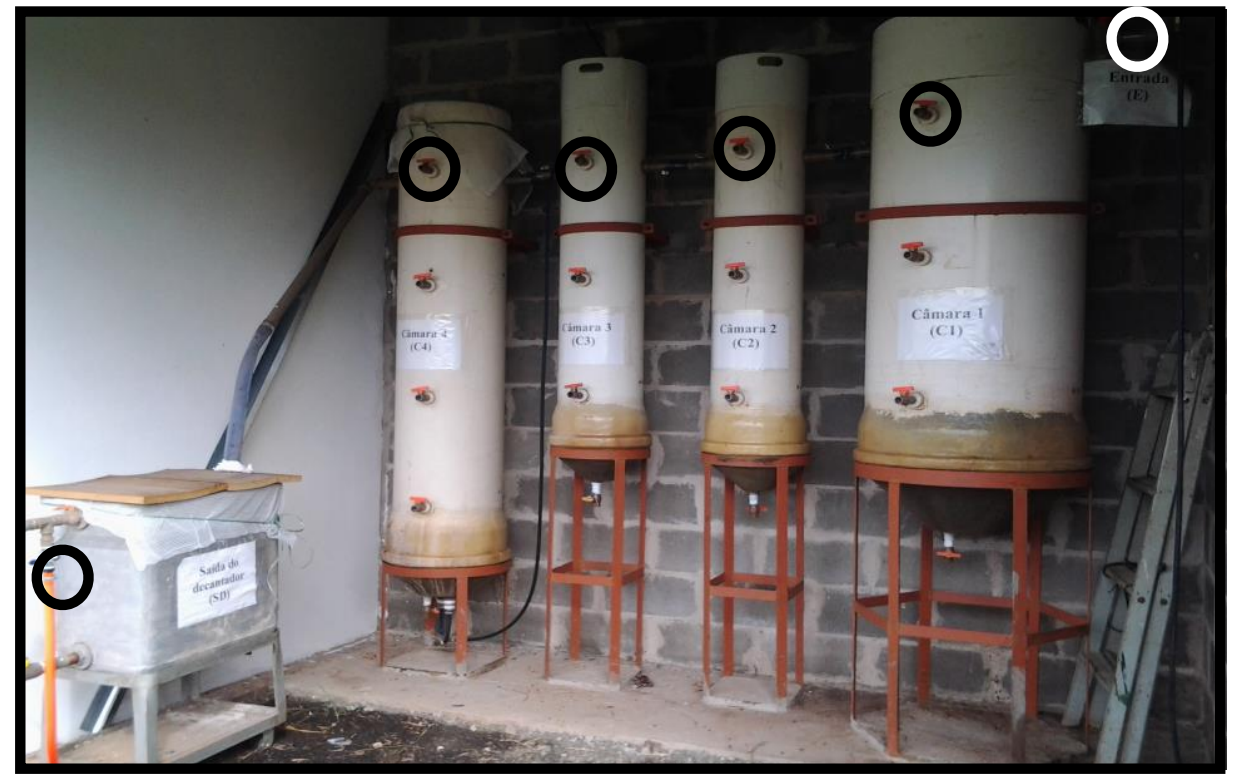

Figura 1: Distribuição das câmaras do reator compartimentado anaeróbio/aeróbio

O fornecimento de ar para a quarta câmara foi realizado por compressor de ar, com sistema de aeração composto por dois difusores de ar colocados junto ao fundo da câmara, de plástico microporoso, com as seguintes dimensões: $75 \mathrm{~mm}$ de diâmetro (base) e $70 \mathrm{~mm}$ de altura em formato cônico (porosidade de $10 \mu \mathrm{m}$ ). Este sistema começou a funcionar após a terceira semana de operação, devido a problemas de instalação. Na quarta câmara, foi adicionado ao topo, anéis de Bambusa vulgaris de $5 \mathrm{~cm}$ de diâmetro, que funcionaram como meio suporte para bactérias. Estão localizados a $50 \mathrm{~cm}$ abaixo do topo da câmara, fixados no local por grades de metal. Após a saída do reator existe um decantador secundário laminar constituído por uma caixa de fibro cimento com 80 L de volume (Fig. 1). As lâminas internas são de polipropileno, e estão dispostas em ângulo de $60^{\circ}$ em relação à horizontal. O reator compartimentado anaeróbio/aeróbio foi alimentado com efluente coletado do DEF, Moradia Estudantil e Associação dos Servidores da Unesp de Bauru. A vazão média diária de esgoto é de aproximadamente $10.000 \mathrm{~L} \mathrm{dia}^{-1}$ e as características físico-químicas podem ser observadas por meio da Tabela 2.

Tabela 2 - Características do efluente a ser tratado pelo reator compartimentado anaeróbio/aeróbio

\begin{tabular}{ccc} 
Parâmetros & Período de férias & Período de aula \\
\hline Ácidos voláteis $\left(\mathrm{mg} . \mathrm{L}^{-1}\right)$ & 73 & 84 \\
Alcalinidade $\left(\mathrm{mg} . \mathrm{L}^{-1}\right)$ & 188 & 234 \\
DQO $\left(\mathrm{mg} . \mathrm{L}^{-1}\right)$ & 140 & 170 \\
$\mathrm{pH}$ & 7,21 & 7,27 \\
Temperatura $\left({ }^{\circ} \mathrm{C}\right)$ & 27 & 28 \\
\hline
\end{tabular}


A partida do reator foi realizada com a inoculação de lodo proveniente de reator UASB da Estação de Tratamento de Esgoto "Candeia", pertencente ao Departamento de Água e Esgoto de Bauru (DAE). O lodo foi aclimatado ao esgoto, seguindo a metodologia descrita em Chernicharo (1997). O período de estabilização do reator, necessário à partida, durou 8 semanas, com início em Janeiro de 2014. Após este período foi dada a sequência no monitoramento do reator, dividido em quatro fases, com diferentes tempos de detenção hidráulica (TDH), com duração aproximada de 6 semanas para cada fase. Os dados apresentados nesta pesquisa são os referentes à Fase 1: $\mathrm{TDH}_{\text {total }}$ igual a 33 horas, com vazão controlada em $24 \mathrm{~L}^{\mathrm{h}} \mathrm{h}^{-1}$. As fases de monitoramento das etapas futuras, juntamente com seus respectivos TDHs, estão descritos na Tabela 3.

Tabela 3: Fases de monitoramento do reator compartimentado anaeróbio/aeróbio, e seus respectivos tempos de detenção hidráulica.

\begin{tabular}{|c|c|c|c|c|c|}
\hline \multirow{3}{*}{ Fases } & \multicolumn{5}{|c|}{ Tempo de detenção hidráulica (horas) } \\
\hline & \multicolumn{3}{|c|}{ Câmaras Anaeróbias } & \multirow{2}{*}{$\begin{array}{c}\text { Câmara Aeróbia } \\
\text { C4 }\end{array}$} & \multirow[t]{2}{*}{ Tota } \\
\hline & $\mathrm{C} 1$ & $\mathrm{C} 2$ & C3 & & \\
\hline 1 & 12 & 6 & 6 & 9 & 33 \\
\hline 2 & 8 & 4 & 4 & 6 & 22 \\
\hline 3 & 6 & 3 & 3 & 4,5 & 16,5 \\
\hline 4 & 3 & 1,5 & 1,5 & 2,25 & 8,25 \\
\hline
\end{tabular}

Os testes laboratoriais para verificar o comportamento e desempenho do reator durante a partida seguiram a metodologia baseada em Rice et al. (2012), para análises de DQO, pH e temperatura. As análises de ácidos voláteis foram realizadas de acordo com a metodologia de Duarte et al.(2006) e as análises de alcalinidade foram feitas de acordo com a metodologia de Ripley et al. (1986). A amostragem foi realizada de forma composta, durante 4 horas, semanalmente. Os pontos de amostragem estão simbolizados por círculos na Figura 1, sendo a Entrada (E), Câmara 1 (C1), Câmara 2 (C2), Câmara 3 (C3), Câmara 4 (C4) e Saída do decantador (SD).

\section{RESULTADOS E DISCUSSÕES}

\subsection{Análise do sobrenadante}

Segundo Chernicharo (1997), os valores aceitáveis dos parâmetros para realizar a partida e monitoramento de reatores são: $\mathrm{pH}$ entre 6,8 e 7,4; ácidos voláteis abaixo de 200 mg. $\mathrm{L}^{-1}$ (como ácido acético); temperatura entre $30-35^{\circ} \mathrm{C}$; alcalinidade abaixo de $400 \mathrm{mg}$. $\mathrm{L}^{-1}$. Os resultados das análises de verificação do sobrenadante estão apresentados na Tabela 3.

Tabela 3. Resultados das análises do lodo de inoculação 


\begin{tabular}{|c|c|c|c|c|c|c|c|}
\hline \multirow{2}{*}{\multicolumn{4}{|c|}{$\begin{array}{l}\text { Sobrenadante (Reator com volume parcial) } \\
\text { Câmaras }\end{array}$}} & \multicolumn{4}{|c|}{ Sobrenadante (Reator com volume total) } \\
\hline & & & & \multicolumn{4}{|c|}{ Câmaras } \\
\hline Parâmetros & C1 & $\mathrm{C} 2$ & C3 & Parâmetros & C1 & $\mathrm{C} 2$ & $\mathrm{C} 3$ \\
\hline Ac. Voláteis (mg.L-1) & 72 & 72 & 71 & Ac. Voláteis (mg.L-1) & 168 & 120 & 96 \\
\hline Alcalinidade (mg.L $\left.{ }^{-1}\right)$ & 328 & 288 & 282 & Alcalinidade (mg.L ${ }^{-1}$ ) & 300 & 284 & 280 \\
\hline DQO (mg.L $\left.{ }^{-1}\right)$ & 103 & 38 & 20 & DQO (mg.L $\left.{ }^{-1}\right)$ & 100 & 30 & 18 \\
\hline pH & 7,1 & 7,1 & 7,1 & pH & 7,3 & 7,3 & 7,4 \\
\hline Temperatura $\left({ }^{\circ} \mathrm{C}\right)$ & 27 & 28 & 28 & Temperatura $\left({ }^{\circ} \mathrm{C}\right)$ & 26 & 27 & 26 \\
\hline
\end{tabular}

Comparando-se os resultados do sobrenadante com os valores aceitáveis sugeridos por Chernicharo (1997), verificou-se que olodoestava adequado para a inoculação, dando-se inicio a partida do reator. Somente a temperatura estava pouco abaixo da faixa ótima para crescimento de microrganismos, porém se encontrava na faixa mesofílica.

\subsection{Monitoramento do sistema}

pH:Os resultados do pH durante o período de partida podem ser observado na Figura 2.

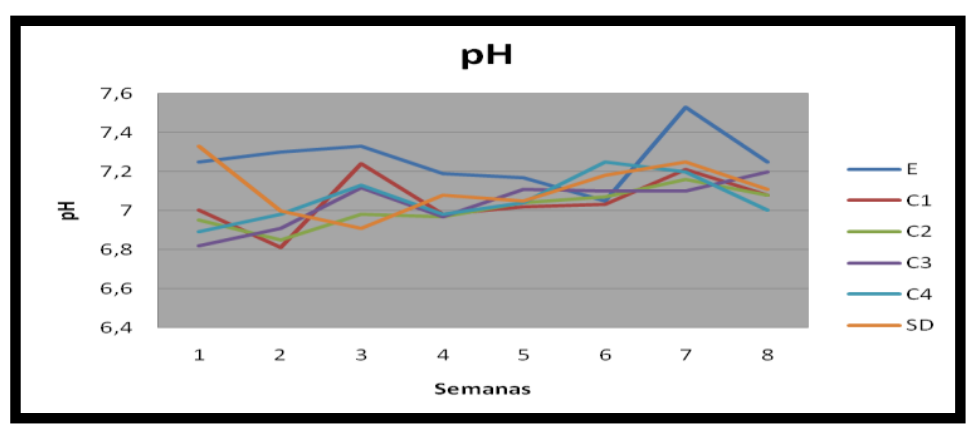

Figura 2: Valores de $\mathrm{pH}$ no reator, durante o período de partida de 8 semanas.

Os valores ideais para o crescimento de bactérias, tanto anaeróbias como aeróbias estão na faixa da neutralidade As bactérias envolvidas nos processos anaeróbios, principalmente as metanogênicas, são bastante sensíveis asmudanças de pH. Segundo Metcalf \& Eddy (1991), o pH ótimo para o crescimento bacteriano está entre 6,5 e 7,5.Pode-se observar na Figura 2, que os valores de $\mathrm{pH}$ da entrada estiveram entre 7,0 e 7,6, já o pH das câmaras anaeróbias (C1, C2 e C3) estiveram entre 6,8 e 7,3 e da câmara aeróbia (C4) esteve entre 6,9 e 7,3. Ainda em relação à atividade microbiana em reatores anaeróbios, a acidogênese é responsável pela produção de ácidos, durante a conversão dos compostos, e como conseqüência, o pH do sistema decai. Estes ácidos por sua vez, são consumidos na metanogênese, ocasionando a elevação do $\mathrm{pH}$. Durante a partida do reator, houve queda dos valores médios $\mathrm{pH}$ entre a entrada e Câmara 1 e 2, decaindo de 7,25 para 7,0, havendo em seguida, uma elevação desses valores nas câmaras C3, e C4, com 7,05 e 7,10 respectivamente. Este comportamento é justificado pela atividade microbiana, que é característico da acidogênese e metanogênese. 
Ácidos Voláteis e Alcalinidade:A interação da alcalinidade com os ácidos voláteis durante a digestão anaeróbia, fundamenta-se na capacidade da alcalinidade do sistema em neutralizar os ácidos formados no processo e também tamponar o $\mathrm{pH}$ na eventualidade de acumulação de ácidos voláteis (CHERNICHARO, 1997). As Figura 3 (A) e (B) apresentam o comportamento dos ácidos voláteis e da alcalinidade ao longo do reator compartimentado, durante as 8 semanas de monitoramento referente a partida. A alcalinidade apresentou valores médios entre $118 \mathrm{mg} . \mathrm{L}^{-1} \mathrm{e}$ $230 \mathrm{mg} . \mathrm{L}^{-1}$, decaindo ao longo do reator, e elevando-se na quarta câmara e saída do decantador. Já os ácidos voláteis apresentou valores médios ente $31 \mathrm{mg} . \mathrm{L}^{-1}$ e $76 \mathrm{mg} . \mathrm{L}^{-1}$.

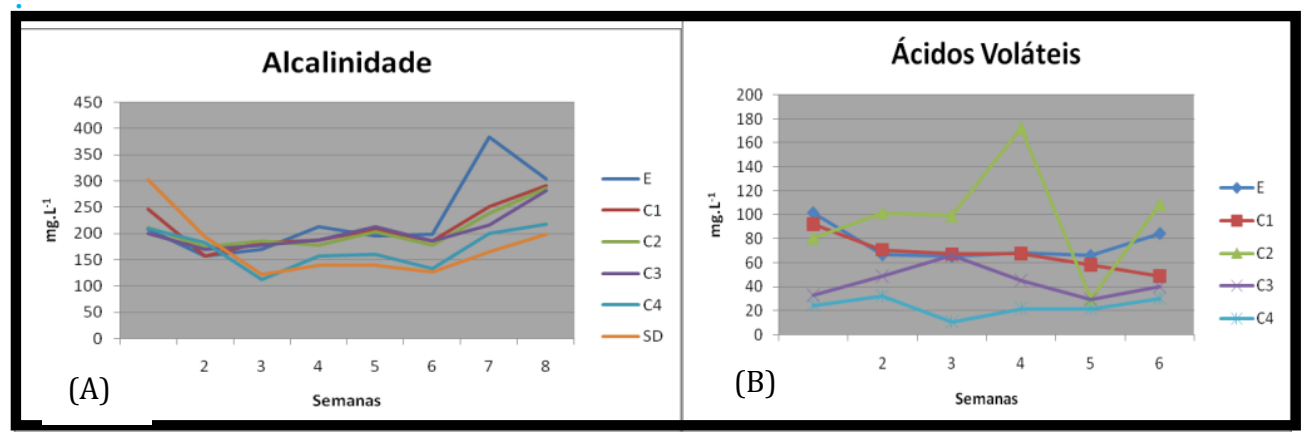

Figura 3: (A): Valores de alcalinidade no reator, durante o período de partida 8 semanas. (B) Valores de ácidos voláteis no reator, durante o período de partida de 8 semanas.

Analisando os resultados de ácidos voláteis, nota-se que os valores da câmara 2 são mais elevados em relação aos outros pontos de amostragem, variando entre $80 \mathrm{mg} . \mathrm{L}^{-1}$ e $100 \mathrm{mg} . \mathrm{L}^{-1}$, característico da fase acidogênica. Este fato comprova a queda de $\mathrm{pH}$, ocorrida entre a Entrada e Câmara 2 (Fig. 3). Pode-se observar que a alcalinidade foi suficiente para tamponar os ácidos gerados pela acidogênese, já que os valores de ácidos voláteis das câmaras 3 e 4, estão abaixo da câmara 2, Os ácidos voláteis nestas câmaras variou entre $29 \mathrm{mg} . \mathrm{L}^{-1}$ e $66 \mathrm{mg} . \mathrm{L}^{-1}$ emC3 e $10 \mathrm{mg} . \mathrm{L}^{-1} \mathrm{e}$ $32 \mathrm{mg} . \mathrm{L}^{-1}$ em C4. A mudança de fase anaeróbia para aeróbia fez com que os níveis de ácidos voláteis fossem bastante baixos independentemente dos valores registrados na fase anaeróbia, pois os ácidos voláteis foram consumidos na metanogênese e não são produzidos na digestão aeróbia.

Demanda química de oxigênio: $O$ valor médio de entrada de DQO foi de $177 \mathrm{mg} . \mathrm{L}^{-1}$. Os valores médios de remoção de DQO durante a partida do reator foram de 58\% de DQO para a fase anaeróbia e de $76 \%$ para remoção total do sistema. Os valores de $\mathrm{DQO}_{\text {total}}$, no sistema, variaram entre $25 \mathrm{mg}^{-1}$ e $250 \mathrm{mg} \mathrm{L}^{-1}$. Os resultados de DQO, ao longo do reator, durante o período de partida estão descritos na Figura 5. 


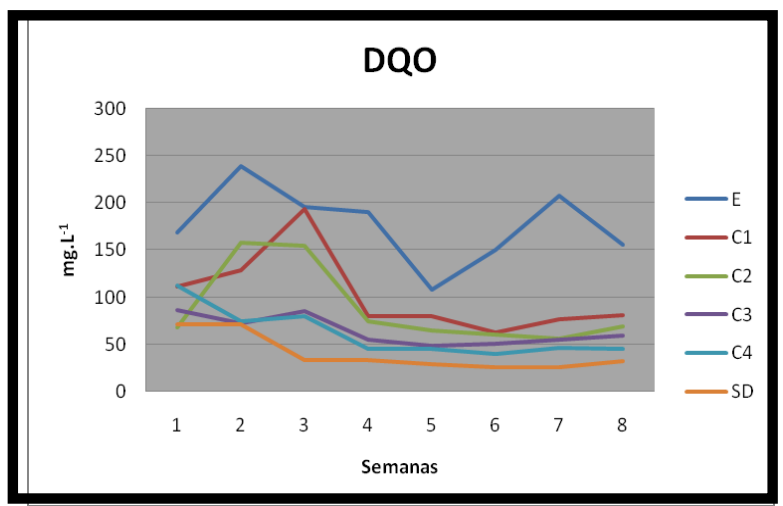

Figura 5:Valores de DQO no reator, durante o período de partida 8 semanas.

Temperatura: A temperatura é o fator físico que mais interfere na seleção de espécies e na taxa de crescimento nos processos anaeróbios, já que os microrganismos não possuem um meio de controlar a própria temperatura, dependendo do meio em que estão (CHERNICHARO, 1997). Os reatores anaeróbios são operados, em sua maioria, em temperaturas mesofílicas, na faixa entre $30^{\circ} \mathrm{C}$ a $37^{\circ} \mathrm{C}$ (SPEECE, 1996). A temperatura do efluente, durante o período de partida variou entre $24^{\circ} \mathrm{C}$ e $30^{\circ} \mathrm{C}$, situando-se na faixa mesofílica, fase ótima para o sistema. Não houve alterações bruscas na temperatura, permanecendo uniforme dentro do reator.

\section{CONCLUSÕES}

Baseando-se nos resultados obtidos nas análises realizadas para a partida da nova configuração do reator compartimentado anaeróbio/aeróbio, pode-se concluir que o reator se mostrou eficiente em relação à remoção de matéria orgânica, com remoção de $\mathrm{DQO}_{\text {total }}$, no sistema completo, de $76 \%$, valor considerado bom para reatores em processo de partida. Os valores de $\mathrm{pH}$ se mantiveram dentro da faixa ótima $(6,8$ a 7,2$)$, não estando em nenhum momento próximo de valores prejudiciais a atividade microbiana.Os ácidos voláteis se mostraram em equilíbrio, sendo produzido na fase anaeróbia, mais especificadamente na acidogênese e permanacendo abaixo na fase aeróbia, após consumo na metanogênese, sendo um bom indicador de um adequado funcionamento do reator. Os resultados da pesquisa mostraram que a nova configuração do reator anaeróbio/aeróbio, se adequou a etapa de partida, sendo promissor para o tratamento de esgoto sanitário em pequenas comunidades. A partir dos resultados da partida foi possível dar sequência ao monitoramento do reator, seguindo com as fases seguintes, com diferentes tempos de detenção hidráulica.

\section{REFERÊNCIAS BIBLIOGRÁFICAS}

BOOPATHAY, R. TILCHE, A. Anaerobic digestion of high strength molasses wastewater using hybrid anaerobic baffled reactor, Water Research, v.25, n.7, p.785-790. 1991.

CHERNICHARO, C. A. L., Principios do Tratamento Biologico de Aguas Residuarias - Reatores Anaerobios. Belo Horizonte: Departamento de Engenharia Sanitaria e Ambiental, Universidade Federal de Minas Gerais, 1997. 
DUARTE, I. C. S. ; Lorena L. Oliveira ; Andréa P. Buzzini ; ADORNO, M. A. T. ; VARESCHE, M. B. A. . Development of a Method by HPLC to Determine LAS and its Application Anaerobic Reactors. Journal of the Brazilian Chemical Society, v. 17, p. 1360-1367, 2006.

METCALF, L.; EDDY, H. P., Wastewater Engeneering: Treatment, Disposal and Reuse. New York, McGraw-Hill, 3' ed., 1991, 1334 p

NETTO, A.P.de O. Reator anaeróbio-aeróbio de leito fixo, com recirculação da fase líquida, aplicado ao tratamento de esgoto sanitário. 2007. 207 f. Dissertação (Mestrado em Engenharia Civil) - Escola de Engenharia de São Carlos, Universidade de São Paulo, São Carlos. 2007.

NIEHAUS, M.D.; MOORE, S.R.; PATRICK, P.D.; DERR, L.L.; BREYETTE, L.; LIMA, A.A.; GUERRANT, R.L. Early childhood diarrhea is associated with diminished cognitive function 4 to 7 years later in children in a northeast brazilian shantytown. The American Society of Tropical Medicine and Hygiene, v.66, n.5, p.590-593, 2002

RIPLEY, L.E., BOYLE, W. C., CONVERSE, J. C., Improved alkalimetric monitoring for anaerobic digestion of high-strenght wastes. Journal WPCF v.38, p. 406-411. 1986.

SILVA, G.H.R.da, Reator compartimentado anaeróbio/aeróbio, tratando esgoto sanitário: Desempenho e operação. 2001. 209f. Dissertação (Mestrado em Engenharia Civil-Saneamento e Ambiente). Faculdade de Engenharia Civil da Universidade Estadual de Campinas, Campinas, 2001 .

SILVA, G. H. R. da; NOUR, E. A. A.Reator compartimentado anaeróbio/aeróbio: Sistema de baixo custo para tratamento de esgotos de pequenas comunidades.Revista brasileira de Engenharia Agrícola e Ambiental, Campina Grande, v.9, n.2, 2005.

SILVA, G. H. R. da; NOUR, E. A. A.Reator Compartimentado Anaeróbio/Aeróbio Submetido a Quatro Diferentes Tempos de Detenção Hidráulica, In:X Oficina e Simpósio Latino-Americano de digestão anaeróbia, Ouro Preto, Minas Gerais, 2011

SPEECE, R. E., Anaerobic Biotechnology for Industrial Wastewater Treatment. Environmental Science Technology, v. 17, n. 9, p. 416 A- 427 A, 1983.

TRATA BRASIL, Instituto Trata Brasil-Saneamento é Saúde. Benefícios Econômicos da expansão do saneamento brasileiro, 2014. Disponível em:http://tratabrasil.org.br/estudo-destacabeneficios-com-a-expansao-do-saneamento-no-brasil. Acesso em: 03 abril 2014.

UNICEF, OMS. Diarrhea: why children are still dying and what can be done. New York: Unicef, Geneva: OMS, 2009. 58 p.

ZANELLA, L., Partida de um reator compartimentado híbrido anaeróbio/aeróbio tratando esgoto sanitário, 1999, 138 f., Dissertação (Mestrado em Engenharia Civil) - Faculdade de Engenharia Civil, Universidade Estadual de Campinas, Campinas. 1999. 